\title{
Introduction of organic solvent solutions into inductively coupled plasma-atomic emission spectrometry using a microwave assisted sample introduction system
}

\author{
Guillermo Grindlay, Salvador Maestre, Luis Gras and Juan Mora* \\ Received 17th May 2006, Accepted 25th July 2006 \\ First published as an Advance Article on the web 31st August 2006 \\ DOI: $10.1039 / \mathbf{b 6 0 6 9 9 5 a}$
}

A microwave assisted sample introduction system based on the use of a $\mathrm{TM}_{010}$ cavity (MWDS2) has been employed for the introduction of $10 \% \mathrm{w} / \mathrm{w}$ organic solvent solutions in inductively coupled plasma atomic emission spectrometry (ICP-AES). Ethanol, propan-2-ol, formic and acetic acids have been used. Firstly, the effect of the incident microwave power and the sample uptake rate on the emission signal was evaluated. For all matrices tested, the higher emission signals were obtained when operating at the highest microwave power (i.e., $290 \mathrm{~W}$ ) and sample uptake rate $\left(400 \mu \mathrm{L} \mathrm{min}{ }^{-1}\right)$. Results with the MWDS2 were compared with those afforded by a desolvation system based on the use of a domestic microwave oven (MWDS) and by a conventional sample introduction system (CS). The MWDS2 provides the highest emission signals (up to 7 and 17 times higher than those with the MWDS and the CS, respectively). As regards the matrix effects originated by the organic solutions, results demonstrate that the use of a microwave-based sample introduction system, mainly the MWDS2, affords a noticeable reduction in the matrix effects originated by the use of organic solvent solutions in ICP-AES with a conventional sample introduction system. This behaviour can be explained by taking into account the solution transport rates afforded by the different sample introduction systems. For all the analytical lines and matrices tested and operating at $400 \mu \mathrm{L} \mathrm{min}{ }^{-1}$, the MWDS2 gives rise to signal values that are, on average, $1.2 \pm 0.2$ times the signal obtained with water. For the MWDS and the CS, this factor takes values of $1.6 \pm 0.2$ and $2.0 \pm 0.5$, respectively. Transient matrix effects have been observed operating with the MWDS2 when switching between water and an organic matrix solution. These transient effects result in a drift time about 4.5 times higher than those with a CS.

\section{Introduction}

Aqueous solutions, frequently acidic or with a high salt content, are the most common matrices analysed by inductively coupled plasma atomic emission spectrometry (ICPAES). However, there are several circumstances in which the introduction of pure organic solvents or water-organic solvent mixtures into the ICP are required: (i) for the direct analysis of trace elements in organic samples such as oils or petroleum products; ${ }^{1,2}$ (ii) after a sample pre-treatment (sample dissolution, solvent extraction, etc.) ${ }^{2}$ and (iii) after a previous chromatographic step in the analysis of environmental, biological, metabolic and pharmaceutical samples. ${ }^{3,4}$

Organic solutions are a well-known source of matrix effects in ICP-AES. ${ }^{5-8}$ Spectral interferences due to the presence of organic solvents in the plasma are, usually, not a limiting consideration for trace elements analysis by ICP-AES, since there are a relatively low number of analytical lines that suffer from potential spectral interferences. ${ }^{9,10}$ Nonetheless, non-spectral matrix interferences are more significant and

Departamento de Química Analítica, Nutrición y Bromatología, Universidad de Alicante, P.O. Box 99, 03080 Alicante, Spain. E-mail: juan.mora@ua.es can arise from the following factors. (1) Changes in the aerosol generation process. The presence of organic solvents modifies the solution's physical properties that mainly affect the pneumatic nebulization process, i.e., surface tension and viscosity. ${ }^{11}$ As a result, aerosols become finer than those obtained with plain water solutions. ${ }^{12}$ Similar results have been reported using different types of nebulizers. ${ }^{13}$ (2) Changes in the intensity of some aerosol transport phenomena that take place during its path to the excitation cell. Organic solvents used show lower density and higher volatility than water, thus contributing, together with the finer aerosols generated, to enhancing the amount of analyte loading the plasma. ${ }^{9}$ (3) Changes in the plasma excitation conditions. The nebulization of organic solvent solutions results in a noticeable enhancement of the amount of solvent reaching the plasma. Therefore, the plasma excitation conditions might be deteriorated. ${ }^{14-16}$

To avoid, or at least to reduce, the matrix effects caused by organic solvents, some approaches have been reported. Among them: (i) appropriate selection of some experimental/ instrumental variables (gas flow rates, rf power, plasma observation zone, diameter of the injector tube, etc.) ${ }^{16,17}$ (ii) addition of oxygen and/or nitrogen to the nebulizer and outer gas flows, ${ }^{16,18-20}$ (iii) use of low-flow sample introduction 
systems, ${ }^{18,19,21-23}$ cooled spray chambers ${ }^{24,25}$ and/or desolvation systems. $^{13,15,26-28}$

A microwave-based desolvation system (MWDS) for use in ICP-based techniques has been developed by our research group. ${ }^{29}$ This device has been successfully applied to the analysis of aqueous and acid solutions both in ICP-AES ${ }^{29,30}$ and ICP mass spectrometry (ICP-MS). ${ }^{31}$ In these conditions, the MWDS gives rise to lower limits of detection (LODs) than a conventional desolvation system (i.e., a heated spray chamber coupled to a condensation unit) and of the same order of magnitude as a commercial infrared-based device. ${ }^{30}$ When being compared with an electrothermal vaporization system, results in ICP-MS have indicated that the MWDS provides the lowest LODs for the isotopes that do not suffer from spectral interferences. $^{32}$ Nevertheless, in spite of its advantages, the system shows several drawbacks due to the inefficient heating process. In addition, the analytical behaviour of the MWDS strongly depends on the sample composition. ${ }^{30,31}$ Recently, a new and more appropriate design that overcomes the main experimental drawbacks shown by the older one has been presented (MWDS2). ${ }^{33}$ The main advantages of the MWDS2 can be summarized as: (i) precise control of the incident and reflected microwave power; and (ii) adequate microwave cavity that makes it appropriate for the aerosol heating. ${ }^{33}$ Using aqueous solutions, the MWDS2 provides higher analytical signals and lower limits of detection and stabilization times than those obtained with the former system both in ICP-AES and ICP-MS.

The goal of the present work is to evaluate the behaviour of the MWDS2 for the introduction of organic solutions into ICP-AES. To this end, several organic solvent solutions (alcohols and organic acids) have been tested. The effect of sample uptake rate and microwave incident power on the ICPAES emission signal has been studied. Matrix effects originated by these solutions in ICP-AES have also been studied and compared with those observed using a different sample introduction system: the former version of the MWDS2, i.e., the MWDS, and a conventional system.

\section{Experimental}

\section{Reagents and samples}

Test solutions containing $1 \mu \mathrm{g} \mathrm{mL} \mathrm{m}^{-1}$ of each element were prepared by diluting aliquots from a $1000 \mu \mathrm{g} \mathrm{mL}^{-1}$ multielemental reference solution (ICP IV, Merck, Darmstadt, Germany) in the appropriate solvent: plain water and $10 \%$ $\mathrm{w} / \mathrm{w}$ aqueous solutions of acetic acid, formic acid, ethanol and propan-2-ol. Analytical grade organic solvents were obtained from Merck (Darmstadt, Germany). These solvents were chosen depending on their applicability in ICP analysis, physical properties and microwave heating capability.

\section{Sample introduction systems}

A pneumatic concentric nebulizer (Model TR-30-A3, Meinhard, Santa Ana, CA, USA) was used in all cases. Sample was delivered to the nebulizer by means of a peristaltic pump (Model Minipulse 3, Gilson, Villiers-Le-Bel, France) at a controlled uptake rate $\left(Q_{1}\right)$. To this end, organic resistant tubes (SC0470, Ismatec, Labortchnick-Analytik, Glattbrugg, Switzerland) were used. The nebulizer gas flow rate was controlled using a calibrated flow meter (Cole-Palmer Inc. Co., Chicago, IL, USA). Argon was always used as the nebulizer gas.

The nebulizer was coupled to the different microwave assisted sample introduction systems described in detail formerly: the previous design (so-called MWDS) and the MWDS2. ${ }^{29,30,31,33}$ The main difference between the two systems was the microwave cavity employed. The MWDS uses the cavity of a domestic microwave oven, ${ }^{29-31}$ whereas the MWDS2 employs a $\mathrm{TM}_{010}$ microwave cylindrical cavity, specially designed for this purpose. ${ }^{33}$ Its dimensions $(9 \mathrm{~cm}$ inner diameter and $9.5 \mathrm{~cm}$ length) were calculated so as to obtain the maximum microwave field intensity in the spray chamber zone. The cavity has a hollow tuning screw $(4.3 \mathrm{~cm}$ of internal diameter, $0.4 \mathrm{~cm}$ wall thickness and $20.5 \mathrm{~cm}$ length) placed at the center of the cavity to maintain the resonance frequency at (or close to) the nominal magnetron one. All components were built of bronze by the support services of the University of Alicante. The aerosols emerging from the microwave cavities were introduced into a condensation unit consisting of two Liebig-type condensers $(33 \mathrm{~cm}$ long and $1.2 \mathrm{~cm}$ inner diameter) placed in series and operating at $10{ }^{\circ} \mathrm{C}$ and $-1{ }^{\circ} \mathrm{C}$, respectively. Thermostatic baths (Model F3-K, Haake Mess-Technik GmbH. u. Co., Kalsruhe, Germany) were used to control the temperatures of both condensers.

For the sake of comparison, the nebulizer was also coupled to a conventional system (CS) consisting of a Ryton doublepass spray chamber (PerkinElmer, Überlingen, Germany) of $100 \mathrm{~cm}^{3}$ inner volume.

\section{Aerosol drop size distribution measurements}

Aerosol drop size distributions were measured by means of a laser Fraunhofer diffraction system (Model 2600c, Malvern Instruments Ltd., Malvern, Worcestershire, UK). All measurements were made at a downstream distance of $5 \mathrm{~mm}$ from the nebulizer tip to the centre of the laser beam. A lens with focal length of $63 \mathrm{~mm}$, which enables the system to measure droplets with diameters between 1.2 and $118 \mu \mathrm{m}$, was used. The software employed was the version B.0D. Calculations to transform the energy distribution into aerosol size distribution were made using a model-independent algorithm that does not preclude any particular distribution function. A set of five replicates was performed in each case, the precision of these measurements always being lower than $2 \%$.

\section{Analyte transport measurements}

Analyte transport rate $\left(W_{\text {tot }}\right)$ measurements were performed by means of a direct method. ${ }^{34}$ Aerosols were collected on a glass-fibre filter (Type A/E, $47 \mathrm{~mm}$ diameter, $0.3 \mu \mathrm{m}$ pore size, Gelman Sciences, USA) placed above the spray chamber. A $500 \mu \mathrm{g} \mathrm{mL}^{-1} \mathrm{Mn}$ solution was nebulized. The analyte retained after a given period of time was extracted by washing the filters with a $1.0 \%(\mathrm{w} / \mathrm{w})$ nitric acid solution. After that, the total solution mass was made up to $50 \mathrm{~mL}$. Finally, the $\mathrm{Mn}$ concentration in each solution was determined by ICP-AES. 
Table 1 ICP-AES operating conditions

\begin{tabular}{ll}
\hline PerkinElmer Optima 3000 & \\
Rf power/kW & 1.450 \\
Sample uptake rate & Variable \\
Argon flow rate $/ \mathrm{L} \mathrm{min}^{-1}$ & 15 \\
$\quad$ Outer & 0.5 \\
Intermediate & $0.6^{b}, 0.7^{a}$ \\
Nebulizer & $5^{a}, 10^{b}$ \\
View height ALC/mm & 0.8 \\
Diameter of the injector tube/mm & 0.1 \\
Integration time/s & 1.0 \\
Read time/s & \\
& \\
Thermo Jarrell-Ash Atomscan Advantage & 1.550 \\
Rf power/kW & Variable \\
Sample uptake rate & 15 \\
Argon flow rate/L min & \\
Outer & 1.0 \\
$\quad$ Intermediate & 0.6 \\
Nebulizer & 15 \\
View height ALC/mm & 1.5 \\
Diameter of the injector tube/mm & 1.0 \\
Integration time/s & \\
a Optimum value obtained for Mn 257.610 nm operating with both the \\
CS and the MWDS at the different experimental conditions tested. \\
${ }_{b}$ Optimum value obtained for Mn 257.610 nm operating with the \\
MWDS2 at the different experimental conditions tested. \\
\hline
\end{tabular}

A set of three replicates was performed in each case, the precision of these measurements always being lower than $4 \%$.

\section{ICP-AES instrumentation}

Two different ICP-AES instruments were used. A PerkinElmer Optima 3000 ICP-AES system (PerkinElmer, Uberlingen, Germany) was used for measurements of steady state emission signal data. Because of its software facilities, studies about transient matrix effects were performed using an Atomscan Advantage instrument (Thermo Jarrell-Ash, Franklin, MA, USA). The operating conditions used with both systems are summarized in Table 1.

Several atomic lines covering a range of excitation energies, $E_{\text {exc }}$, from $3.14 \mathrm{eV}$ (Al I 396.152) to $4.35 \mathrm{eV}$ (Mg I 285.213) were used. Ionic lines were selected to cover a range of energy sum, $E_{\text {sum }}$ (i.e., sum of the ionization, $E_{\text {ion }}$, and excitation energies) from $7.93 \mathrm{eV}$ (Ba II 455.403) to $14.79 \mathrm{eV}$ (Pb II 220.353). Table 2 shows the wavelengths and energy values of the lines tested.

\section{Results and discussion}

\section{Characterization of the MWDS2 operating with organic solvent solutions}

Effect of the incident microwave power and the sample uptake rate. Fig. 1 shows the effect of the sample uptake rate on the Mn emission signal normalized against the maximum signal value, $I_{\text {nor }}$, for different incident microwave power using the ethanol solution. Results indicate that, for a given $Q_{1}$ (higher than $\left.50 \mu \mathrm{L} \mathrm{min}{ }^{-1}\right), I_{\text {nor }}$ rises when the microwave power is increased. Thus, at the highest $Q_{1}$ tested $\left(400 \mu \mathrm{L} \mathrm{min}{ }^{-1}\right)$, the $\mathrm{Mn}$ emission signal improves by a factor of 5.0 when the microwave power is increased from $100 \mathrm{~W}$ to $290 \mathrm{~W}$. This factor is similar for all the solutions tested (4.6 for propan-2-
Table 2 Elements, wavelengths and energy values for the selected lines tested

\begin{tabular}{llllc}
\hline Element & Wavelength/nm (line type) & $E_{\text {exc }} / \mathrm{eV}$ & $E_{\text {ion }} / \mathrm{eV}$ & $E_{\text {sum }}{ }^{a} / \mathrm{eV}$ \\
\hline $\mathrm{Al}$ & $396.152(\mathrm{I})$ & 3.14 & & 3.14 \\
$\mathrm{Cr}$ & $357.869(\mathrm{I})$ & 3.46 & & 3.46 \\
$\mathrm{Cu}$ & $324.754(\mathrm{I})$ & 3.82 & & 3.82 \\
$\mathrm{Ar}$ & $420.068(\mathrm{I})$ & 3.95 & & 3.95 \\
$\mathrm{Mg}$ & $285.213(\mathrm{I})$ & 4.35 & & 4.35 \\
$\mathrm{C}$ & $193.018(\mathrm{I})$ & 6.22 & & 6.22 \\
$\mathrm{Ba}$ & $455.403(\mathrm{II})$ & 5.21 & 2.72 & 7.93 \\
$\mathrm{Mg}$ & $280.270(\mathrm{II})$ & 7.65 & 4.42 & 12.07 \\
$\mathrm{Mn}$ & $257.610(\mathrm{II})$ & 7.44 & 4.81 & 12.25 \\
$\mathrm{Cr}$ & $267.716(\mathrm{II})$ & 6.77 & 6.16 & 12.93 \\
$\mathrm{Fe}$ & $238.204(\mathrm{II})$ & 5.20 & 7.87 & 13.07 \\
$\mathrm{Co}$ & $228.616(\mathrm{II})$ & 7.86 & 5.84 & 13.70 \\
$\mathrm{Ni}$ & $221.647(\mathrm{II})$ & 7.64 & 6.39 & 14.03 \\
$\mathrm{~Pb}$ & $220.353(\mathrm{II})$ & 7.42 & 7.37 & 14.79 \\
${ }^{a} E_{\text {sum }}$ & ionization energy $\left(E_{\text {ion }}\right)+$ excitation energy $\left(E_{\text {exc }}\right)$. \\
\hline
\end{tabular}

ol, 5.0 for acetic acid and 5.2 for formic acid). To explain this behaviour it must be considered that, for a given $Q_{1}$, increasing the incident microwave power increases the amount of energy absorbed by the system, since the reflected energy remains almost constant (about $15 \mathrm{~W}$ ) in all experiences. Therefore, the aerosol vaporization process improves and, as a consequence, the analyte transport rate $\left(W_{\text {tot }}\right)$ increases. ${ }^{33}$

As regards the effect of $Q_{1}$ on the Mn emission signal, it can be observed in Fig. 1 that, taking into account the signal precision, for a $100 \mathrm{~W}$ microwave incident power, the signal remains constant up to about $200 \mu \mathrm{L} \min ^{-1}$ and then decreases. Using intermediate microwave powers, i.e., $150 \mathrm{~W}$ and $200 \mathrm{~W}$, the signal peaks at $200 \mu \mathrm{L} \mathrm{min}^{-1}$. At the highest power, i.e., $290 \mathrm{~W}$, an increase in the sample uptake rate from 200 to $400 \mu \mathrm{L} \mathrm{min}{ }^{-1}$ does not result in a signal reduction. The behaviour shown in Fig. 1 for the ethanolic solution has also been observed for all the remaining solutions tested. All these results are in agreement with the corresponding analyte transport rate measurements. This behaviour has been previously observed when using desolvation systems based on different heating principles ${ }^{35,36}$ and it can be explained taking into account the fact that increasing $Q_{1}$ : (1) increases the amount of analyte nebulized (this factor would produce an increase in

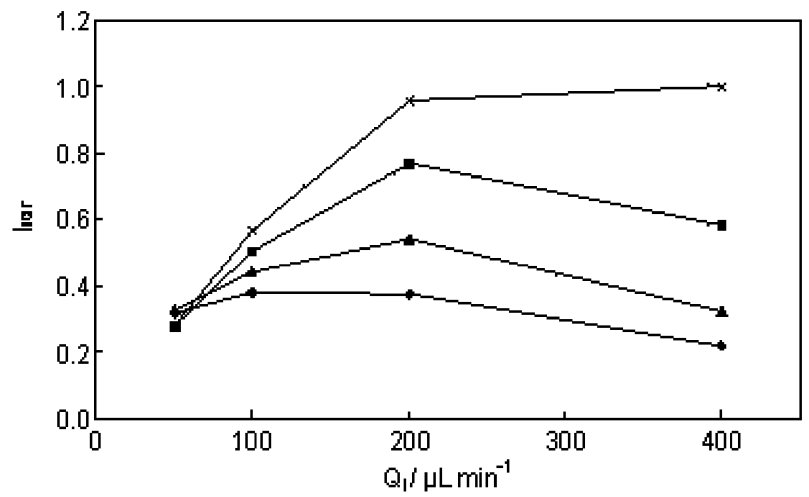

Fig. 1 Effect of the sample uptake rate on the Mn $257.610 \mathrm{~nm}$ normalized emission intensity, $I_{\text {nor }}$, at different incident microwave powers: $(\diamond) 100 \mathrm{~W} ;(\boldsymbol{\Delta}) 150 \mathrm{~W} ;(\boldsymbol{\square}) 200 \mathrm{~W} ;(\times) 290 \mathrm{~W}$. Ethanol 10\% $\mathrm{w} / \mathrm{w}$. 
the amount of solution reaching the plasma); and (2) decreases the vaporization capability of the heating step. This factor is related to the amount of energy available by aerosol mass unit (i.e, to the amount of energy-to-mass ratio, EMR). ${ }^{29-31,33,37}$ Thus, at low microwave incident powers, an increase in $Q_{1}$ gives rise to a decrease in the EMR, thus reducing the aerosol vaporization efficiency of the system. As a consequence, analyte losses along the sample introduction system increase due to: (i) drop impacts against the inner walls of the spray chamber; (ii) turbulence; and (iii) nucleation processes in the condensation unit. $^{30,37}$ Therefore, $W_{\text {tot }}$ and the emission signal peak. On the other hand, at high EMR values the aerosol is efficiently evaporated. These conditions are obtained at low $Q_{1}$ and/or higher microwave incident powers. Thus, for instance, at $50 \mu \mathrm{L}$ $\mathrm{min}^{-1}$ the microwave incident power shows no influence on $I_{\text {nor }}$. Similarly, operating at $290 \mathrm{~W}, I_{\text {nor }}$ rises when increasing $Q_{1}$. In these conditions, the higher the value of $Q_{1}$, the higher the amount of analyte that reaches the plasma. Nevertheless, it is important to highlight that the improvement in the emission signal is lower than that observed with $W_{\text {tot }}$. Thus, operating with the ethanol solution at $290 \mathrm{~W}$, the analyte transport rate improves by a factor of 3.2 when $Q_{1}$ increases from 100 to $400 \mu \mathrm{L} \mathrm{min}{ }^{-1}$. However, in these conditions the signal improvement factor is just 1.8. To explain this behaviour it must be considered that the amount of solvent loading the plasma also increases with $Q_{1}$, thus deteriorating the plasma excitation characteristics. ${ }^{33}$ Solvent transport rates have not been measured since the direct method usually employed is not useful for the retention of organic matrices. In order to estimate the amount of solvent loading the plasma, the $\mathrm{C}$ emission signal has been used. Thus, operating with the ethanol solution at $290 \mathrm{~W}$ incident power, the C emission signal rises by about $24 \%$ when $Q_{1}$ is increased from 100 to $400 \mu \mathrm{L} \mathrm{min}{ }^{-1}$. This result indicates that the amount of solvent reaching the plasma increases when $Q_{1}$ increases.

Comparison with different sample introduction systems. Table 3 compares the $\mathrm{Mn}$ emission intensity obtained for the MWDS2 and the additional sample introduction systems tested for all matrices studied at two different $Q_{1}$ values. From data shown in Table 3 it can be concluded that, in general terms, the MWDS2 gives rise to the highest emission signals (i.e., intensity ratios within the 0.9-17.1 range). The signal improvement factor obtained depends on $Q_{1}$ and on the sample introduction system. Thus, when comparing the results obtained with the microwave-based devices (i.e., MWDS and MWDS2), it can be concluded that working at $100 \mu \mathrm{L} \mathrm{min}^{-1}$ the Mn emission signals obtained with both systems are similar irrespective of the matrix considered. At the highest $Q_{1}$ tested (i.e., $400 \mu \mathrm{L} \min ^{-1}$ ), signals obtained with the MWDS2 are between 5 and 7 times higher than those with the MWDS, depending on the matrix used. These results are in agreement with those expected from $W_{\text {tot }}$. When comparing with the CS, data from Table 3 indicate that the MWDS2 always gives rise to the highest emission signals (between 4 and 17 times higher) than the CS. For a given matrix, the signal improvement factor is higher at the highest $Q_{1}$. Again, this behaviour is in agreement with that observed in $W_{\text {tot }}$. Nonetheless, it is important to note that when comparing with the $\mathrm{CS}$, the signal improvement factors are lower than those
Table 3 Comparison of the Mn emission intensities obtained for the different sample introduction systems and matrix studied at different sample uptake rates

\begin{tabular}{|c|c|c|c|c|}
\hline & \multicolumn{2}{|c|}{$I_{\mathrm{MWDS} 2} / I_{\mathrm{MWDS}}$} & \multicolumn{2}{|c|}{$I_{\mathrm{MWDS} 2} / I_{\mathrm{CS}}$} \\
\hline & $\begin{array}{l}100 \mu \mathrm{L} \\
\min ^{-1}\end{array}$ & $\begin{array}{l}400 \mu \mathrm{L} \\
\min ^{-1}\end{array}$ & $\begin{array}{l}100 \mu \mathrm{L} \\
\min ^{-1}\end{array}$ & $\begin{array}{l}400 \mu \mathrm{L} \\
\min ^{-1}\end{array}$ \\
\hline Water & 1.3 & 7.3 & 8.2 & 17.1 \\
\hline Formic acid & 0.9 & 5.4 & 6.4 & 10.6 \\
\hline Acetic acid & 1.0 & 5.8 & 6.8 & 8.7 \\
\hline Ethanol & 1.3 & 5.8 & 4.9 & 5.7 \\
\hline Propan-2-ol & 0.9 & 4.7 & 3.6 & 4.7 \\
\hline
\end{tabular}

observed for $W_{\text {tot }}$. This difference is more pronounced when using organic solutions and working at the highest $Q_{1}$ value. Thus, operating at $400 \mu \mathrm{L} \mathrm{min}{ }^{-1}$, the MWDS2 provides $W_{\text {tot }}$ values between 11.2 (for propan-2-ol) and 17.6 (for plain water) times higher than those with the CS. The signal enhancements are just 4.7 and 17.1 for propan-2-ol and water, respectively. The lack of coincidence between the values of both sets of parameters can be attributed to the greater amount of solvent reaching the plasma provided by the MWDS2. ${ }^{33}$

The limits of detection (LODs) for several lines were calculated according to the approach described by Boumans: ${ }^{38,39}$

$$
\mathrm{LOD}=3(\mathrm{RSD})_{\mathrm{b}} \frac{C_{0}}{\mathrm{SBR}}
$$

where $(\mathrm{RSD})_{\mathrm{b}}$ is the relative standard deviation obtained from twenty replicates of the blank; $C_{0}$ is the analyte concentration of the solution measured; and SBR is the signal-to-background ratio.

Fig. 2 compares the LODs afforded by the MWDS2 with those obtained with the MWDS (Fig. 2A) and the CS (Fig. 2B) using the ethanol solution at different sample uptake rates

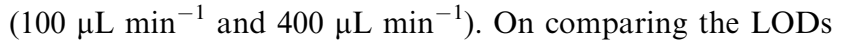
obtained with the different sample introduction systems, results in Fig. 2 indicate that, in general terms, the MWDS2 gives rise to the lowest LODs. The LOD improvement factor depends, for a given emission line, on the sample introduction system and $Q_{1}$ used. Thus, in Fig. 2A it can be seen that operating at $100 \mu \mathrm{L} \mathrm{min}{ }^{-1}$ both microwave-based systems give rise to similar LODs. When working at the highest $Q_{1}$, the MWDS2 gives rise to LODs up to 6.0 times lower (for Fe II, $\mathrm{Mg}$ I, among others) than the MWDS. In comparison with the CS, Fig. 2B shows that the MWDS2 always gives rise to the lowest LODs. Again, the improvement factor is higher at the highest $Q_{1}$. Thus, LODs afforded by the MWDS2 are up to 7 (for $\mathrm{Cr}$ II and $\mathrm{Ba}$ I) and 12 times (for Mn II) higher than those by the CS operating at $100 \mu \mathrm{L} \min ^{-1}$ and $100 \mu \mathrm{L} \mathrm{min} \operatorname{mos}^{-1}$, respectively. Similar behaviour has been observed for all the matrices tested. These results are in agreement with those expected from their relative emission signals (Table 3 ).

\section{Matrix effects due to the presence of organic solvents}

Influence of the sample uptake rate and sample introduction system. Fig. 3 shows the effect of $Q_{1}$ on the Mn emission signal obtained for a given organic matrix related to that obtained 

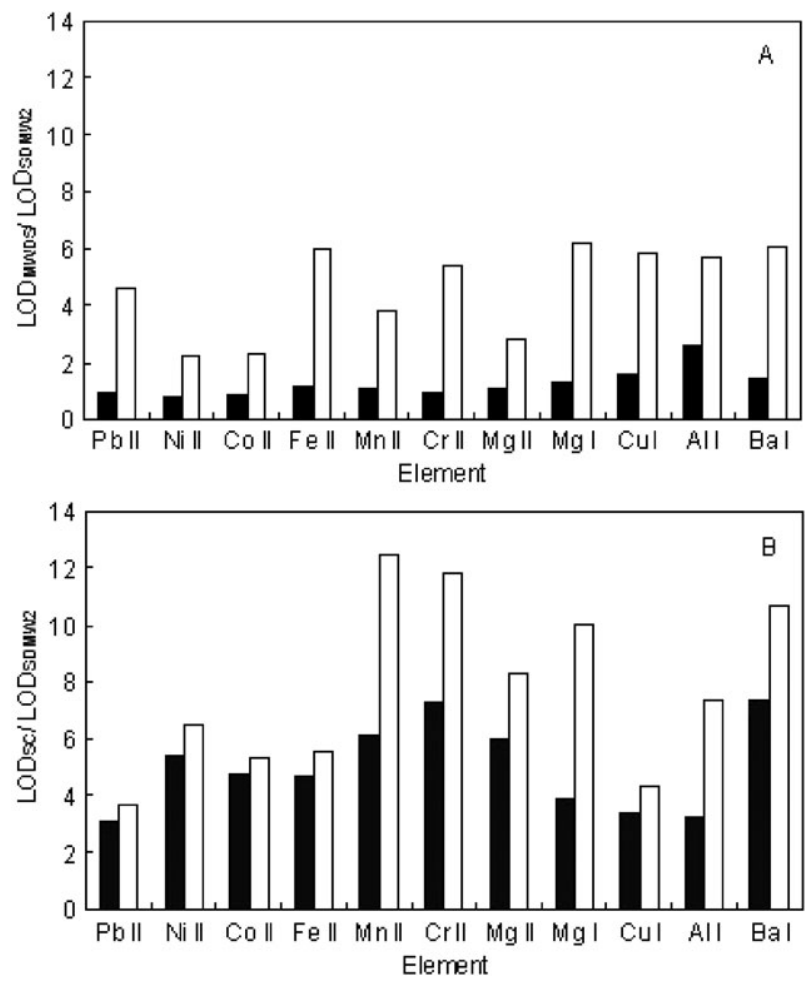

Fig. 2 Limits of detection obtained for different lines and sample introduction systems relative to those with the MWDS2 $(290 \mathrm{~W})$ : (A) MWDS; (B) CS, operating at different sample uptake rates, ( $\mathbf{\square})$ $100 \mu \mathrm{L} \mathrm{min}{ }^{-1}$ and $(\square) 400 \mu \mathrm{L} \mathrm{min}{ }^{-1}$. Ethanol $10 \% \mathrm{w} / \mathrm{w}$.

with water, $I_{\text {rel }}\left(I_{\text {rel }}=I_{\text {matrix }} / I_{\text {water }}\right)$ for all the sample introduction systems evaluated: MWDS2 (Fig. 3A), MWDS (Fig. 3B) and CS (Fig. 3C). Before analyzing the results shown in Fig. 3, it is important to point out that the precision of all these data is, on average, $7 \%$ for $\mathrm{Mn}$ and all the conditions evaluated (with the exception of $50 \mu \mathrm{L} \mathrm{min}{ }^{-1}$, for which the $I_{\text {rel }}$ precision drops up to $20 \%$ ). Therefore, it can be considered that an $I_{\text {rel }}$ value of $1.0 \pm 0.1$ indicates an absence of matrix effects on the emission signal. As regards the behaviour of the MWDS2, in Fig. 3A it can be seen that, for all the solutions tested, there is no clear effect of $Q_{1}$ on $I_{\text {rel }}$. In addition, no noticeable effect of the solvent composition is observed for this sample introduction system. When using the MWDS (Fig. 3B) the trend with $Q_{1}$ is, in general terms, similar to that with the MWDS2, although matrix effects are enhanced. For this device, the sample composition influences the analytical signal, as has previously been reported with inorganic acid solutions. ${ }^{30,31}$ When working with the CS (Fig. 3C), no effect of $Q_{1}$ on $I_{\text {rel }}$ is observed. Nevertheless, there is a noticeable matrix effect on this parameter. Thus, data in Fig. 3C reveals that alcoholic solutions provide higher $I_{\text {rel }}$ values (i.e., higher matrix effects) than organic acid solutions. Hence, the values of $I_{\text {rel }}$ follow the order $\left(I_{\text {rel }}\right)_{\text {propan-2-ol }}>\left(I_{\text {rel }}\right)_{\text {ethanol }}>\left(I_{\text {rel }}\right)_{\text {acetic }}$ $>\left(I_{\text {rel }}\right)_{\text {formic }}$, irrespective of the $Q_{1}$ used.

On comparing the behaviour of the different sample introduction systems, from results in Fig. 3 it can be concluded that the MWDS2 gives rise to the lowest $I_{\text {rel }}$ values (between 0.7 and 1.3), followed by the MWDS (between 1.1 and 1.8) and by the CS for which $I_{\text {rel }}$ takes values from 1.2 up to 2.7. These results indicate that the use of a microwave-based sample introduction system, mainly the MWDS2, affords a noticeable reduction in the matrix effects originating from the use of organic solvent solutions in ICP-AES with a conventional sample introduction system.

In order to explain the above described behaviours, some experiments have been carried out. Firstly, the drop size distributions of the aerosols generated by the nebulizer (primary aerosols) have been measured. Fig. 4 shows the effect of
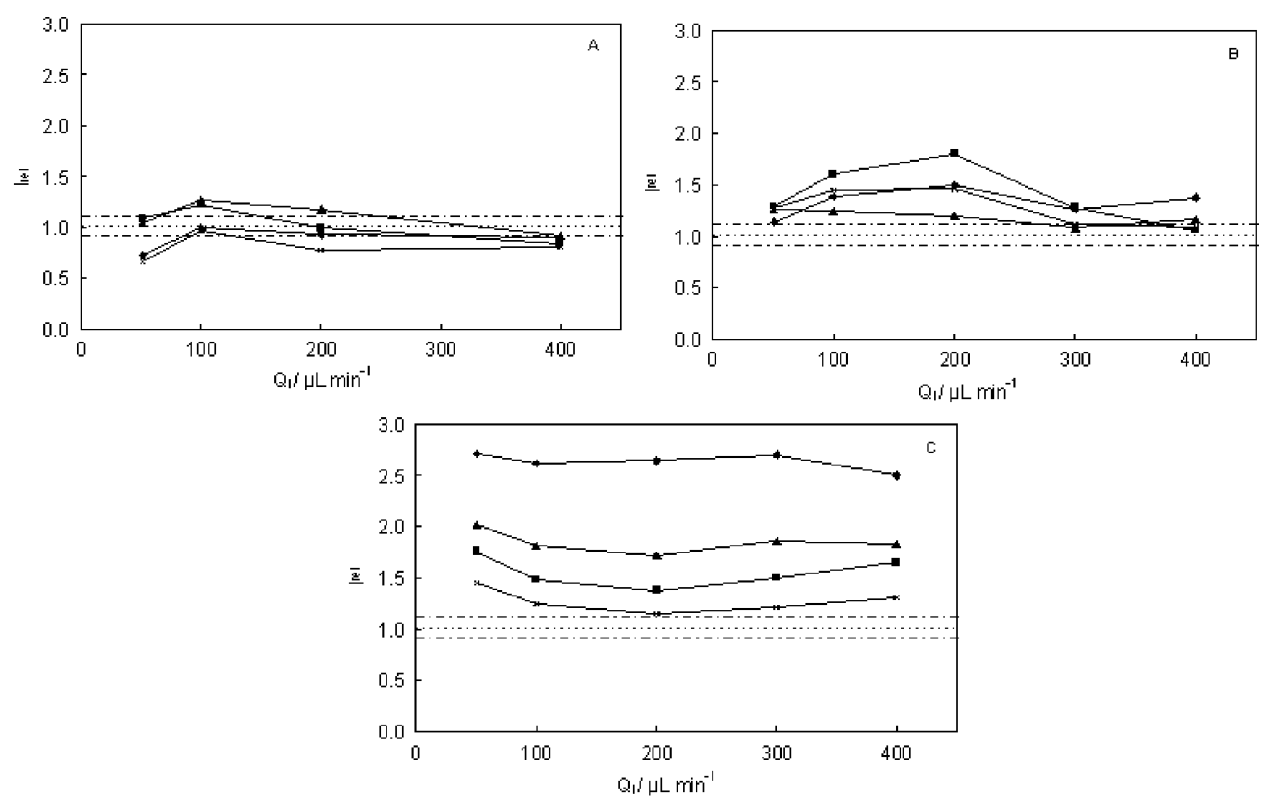

Fig. 3 Effect of the sample uptake rate on the Mn $257.610 \mathrm{~nm}$ net emission signal obtained for the different matrices relative to water, $I_{\text {rel }}:(\times)$ formic acid; ( $\mathbf{\square}$ ) acetic acid; ( $\mathbf{\Delta}$ ) ethanol; $($ ) propan-2-ol; and the different sample introduction systems tested: (A) MWDS2, 290 W; (B) MWDS; (C) CS. 


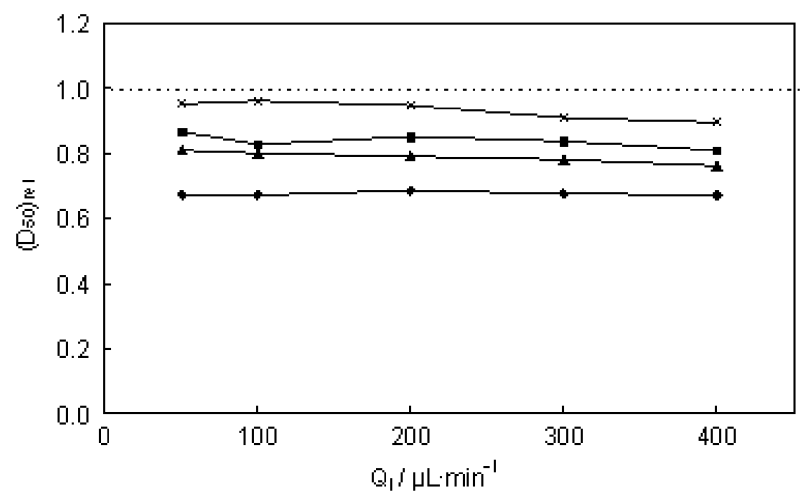

Fig. 4 Effect of the sample uptake rate on the median of the volume drop size distribution of the primary aerosols for the different matrices relative to water $\left(D_{50}\right)_{\text {rel }}:(\times)$ formic acid; $(\boldsymbol{\square})$ acetic acid; $(\mathbf{\Delta})$ ethanol; $(\bullet)$ propan-2-ol.

$Q_{1}$ on the median of the volume drop size distribution $\left(D_{50}\right)$, relative to that obtained with plain water $\left(D_{50}\right)_{\text {rel }}$, for all the organic solvent solutions. In Fig. 4 it can be observed that there is no effect of $Q_{1}$ on $\left(D_{50}\right)_{\text {rel }}$, thus indicating that the effect of this variable on the primary aerosol drop size distribution is independent of the solvent composition. In addition, Fig. 4 also reveals that organic solutions always give rise to $\left(D_{50}\right)_{\text {rel }}$ values lower than 1.0, i.e., aerosols finer than those with plain water solutions. Among the solutions tested, propan-2-ol provides the finest primary aerosols, followed by ethanol and acetic and formic acids. These results are as expected from their respective values of surface tension and viscosity (Table 4). ${ }^{12}$

When running with a microwave-based desolvation system, the efficiency of the aerosol heating step must also be considered in order to understand the signal results. Operating with these systems, aerosol evaporation intensity depends on the following. (i) The aerosol drop size, since the finest droplets are more efficiently vaporized. Douglass et al., ${ }^{40}$ used the Mie scattering theory to evaluate the microwave power absorbed by a single drop of water and to estimate drop heating and solvent vaporization. These authors concluded that vaporization of a single drop due to microwave heating is an inefficient process. Nevertheless, experimental results have shown that an aerosol confined inside a spray chamber interacts with a microwave field. ${ }^{33,41}$ The explanation of these discrepancies seems to be related to the heterogeneity and electrical properties of the aerosols (i.e., charge distribution on droplet surface). ${ }^{42}$ (ii) The dissipation factor $(\operatorname{tg} \delta)$ of the

Table 4 Physical properties of the organic solvent solutions tested relative to those of the plain water $\left(20^{\circ} \mathrm{C}\right)$

\begin{tabular}{lllll}
\hline Solvent & $\sigma_{\mathrm{i}} / \sigma_{\text {water }}{ }^{a}$ & $\eta_{\mathrm{i}} / \eta_{\text {water }}$ & $\alpha_{\mathrm{i}} / \alpha_{\text {water }}$ & $\operatorname{tg} \delta_{\mathrm{i}} / \operatorname{tg} \delta_{\text {water }}$ \\
\hline Formic acid $10 \%$ & 0.90 & 1.07 & 1.06 & 5.87 \\
Acetic acid $10 \%$ & 0.79 & 1.21 & 1.05 & 1.41 \\
Ethanol $10 \%$ & 0.66 & 1.50 & 1.15 & 7.65 \\
Propan-2-ol $10 \%$ & 0.57 & 1.63 & 1.14 & 6.50
\end{tabular}

${ }^{a} \sigma$ : solvent surface tension. $\eta$ : solvent viscosity. $\alpha$ : solvent volatility. $\operatorname{tg} \delta$ : dissipation factor (referred to pure organic solvent at $2450 \mathrm{MHz}$ ).
Table 5 Effect of the sample uptake rate on the analyte transport rate obtained with the different organic solvent solutions relative to that obtained with water, $\left(W_{\text {tot }}\right)_{\text {rel }}$, for the different sample introduction systems studied

\begin{tabular}{|c|c|c|c|c|c|c|}
\hline \multirow[b]{3}{*}{ Solvent } & \multicolumn{6}{|l|}{$\left(W_{\text {tot }}\right)_{\text {rel }}$} \\
\hline & \multicolumn{2}{|c|}{ SDMW2 } & \multicolumn{2}{|l|}{ SDMW } & \multicolumn{2}{|l|}{$\mathrm{CS}$} \\
\hline & $\begin{array}{l}100 \mu \mathrm{L} \\
\min ^{-1}\end{array}$ & $\begin{array}{l}400 \mu \mathrm{L} \\
\min ^{-1}\end{array}$ & $\begin{array}{l}100 \mu \mathrm{L} \\
\min ^{-1}\end{array}$ & $\begin{array}{l}400 \mu \mathrm{L} \\
\min ^{-1}\end{array}$ & $\begin{array}{l}100 \mu \mathrm{L} \\
\min ^{-1}\end{array}$ & $\begin{array}{l}400 \mu \mathrm{L} \\
\min ^{-1}\end{array}$ \\
\hline Formic acid & 1.1 & 1.2 & 1.4 & 1.3 & 1.1 & 1.1 \\
\hline Acetic acid & 1.1 & 1.6 & 1.5 & 1.4 & 1.8 & 1.7 \\
\hline Ethanol & 1.1 & 1.8 & 1.7 & 1.3 & 2.0 & 1.8 \\
\hline Propan-2-ol & 1.1 & 1.9 & 1.8 & 1.6 & 2.5 & 2.5 \\
\hline
\end{tabular}

different matrices (Table 4): thus, the higher the $\operatorname{tg} \delta$ value, the higher the efficiency of the microwave heating process. In general, organic matrices show higher $\operatorname{tg} \delta$ than water (Table 4) and thus are more efficiently evaporated. ${ }^{33,42}$ (iii) The microwave cavity employed: due to the poor heating efficiency of the MWDS, the above mentioned effects are more significant than when operating with the MWDS2, thus influencing the performance of both the heating and condensation units and, therefore, the analytical behaviour.

Table 5 shows the analyte transport rates obtained for all the matrices studied relative to water, $\left(W_{\mathrm{tot}}\right)_{\mathrm{rel}}\left(\left(W_{\mathrm{tot}}\right)_{\mathrm{rel}}=\right.$ $\left.\left(W_{\text {tot }}\right)_{\text {matrix }} /\left(W_{\text {tot }}\right)_{\text {water }}\right)$ for two different $Q_{1}$ and all sample introduction systems tested. From the results given in Table 5 it can be concluded that when using the CS, there is no effect of $Q_{1}$ on $\left(W_{\text {tot }}\right)_{\text {rel }}$ for all the solvents studied. For a given $Q_{1}$, propan-2-ol affords the higher $\left(W_{\text {tot }}\right)_{\text {rel }}$ values followed by ethanol, acetic and formic acids. These results are as expected taking into account the characteristics of the aerosols generated and the solvent volatilities (Table 4). Consequently, the behaviour observed in $I_{\text {rel }}$ (Fig. 3C) is in agreement with that in $\left(W_{\text {tot }}\right)_{\text {rel }}$. Running with the MWDS2, and for a given matrix, an increase in $Q_{1}$ results in an increase in $\left(W_{\text {tot }}\right)_{\text {rel }}$, meaning that the matrix effect enhances when the sample uptake rate rises. As regards the effect of the matrix nature, Table 5 shows that when operating with the MWDS2 at 100 $\mu \mathrm{L} \min ^{-1},\left(W_{\text {tot }}\right)_{\text {rel }}$ remains constant $(1.1)$ irrespective of the solvent used, thus indicating similar values to those obtained with water. At the highest $Q_{1}$ tested, i.e., $400 \mu \mathrm{L} \min ^{-1}$, $\left(W_{\text {tot }}\right)_{\text {rel }}$ depends on the matrix considered. In these conditions, $\left(\left(W_{\text {tot }}\right)_{\text {rel }}\right)_{\text {propan-2-ol }}>\left(\left(W_{\text {tot }}\right)_{\text {rel }}\right)_{\text {ethanol }}>\left(\left(W_{\text {tot }}\right)_{\text {rel }}\right)_{\text {acetic }}$ $>\left(\left(W_{\text {tot }}\right)_{\text {rel }}\right)_{\text {formic }}$. These results are in clear disagreement with those observed in $I_{\text {rel }}$ (Fig. 3A), for which this parameter remains almost constant when $Q_{1}$ is increased and very little effect of the matrix is observed. The behaviour shown by the MWDS is intermediate between those observed with the MWDS2 and the CS. To explain the lack of correspondence between the values of analyte transport rates and emission signals shown by the microwave-based systems, it must be taken into account that the excitation characteristics of the plasma depend on the sample introduction system, since the amount of solvent loading the plasma can be different. To evaluate the plasma characteristics, different experiments have been performed. Firstly, the Mg II/Mg I lines ratios have been measured for all the sample introduction systems and conditions tested. For a given sample introduction system, this 

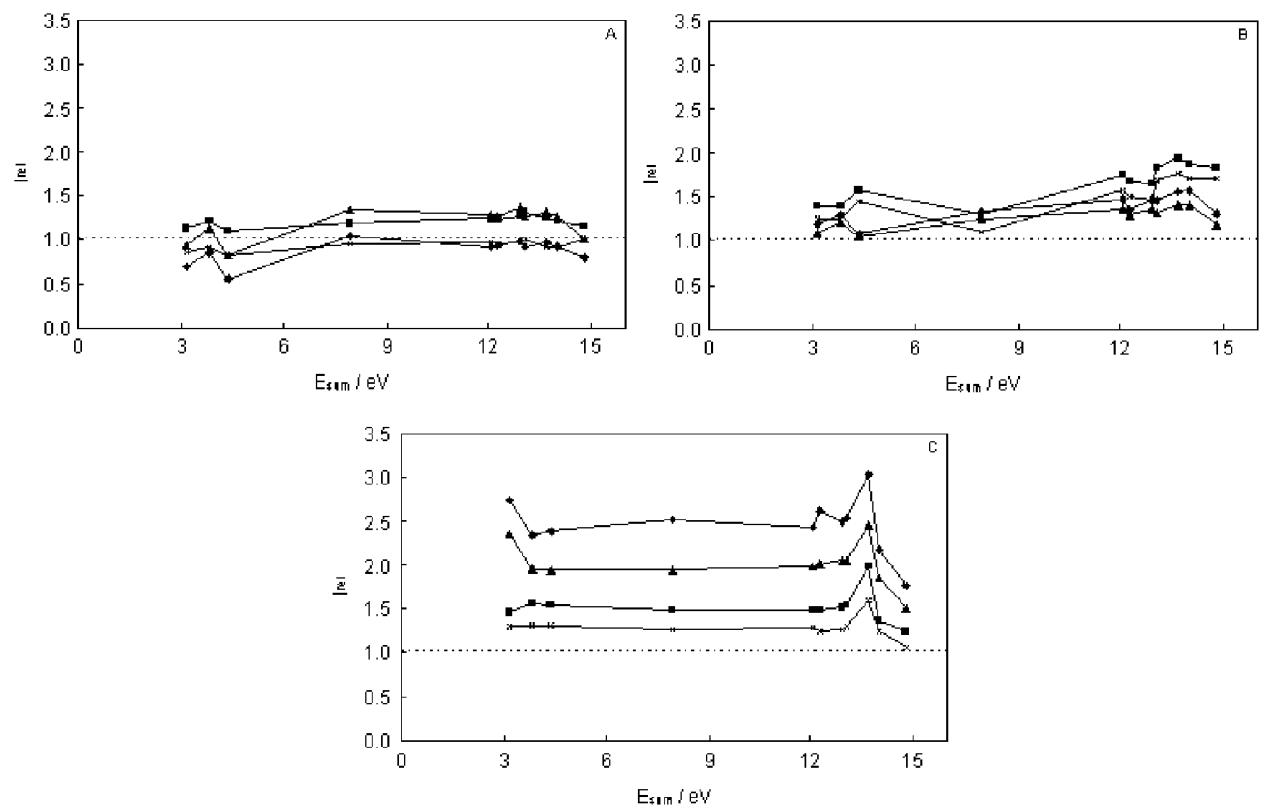

Fig. 5 Effect of the line energy on the net emission signal obtained for the different matrices relative to water, $I_{\text {rel }}:(\times)$ formic acid; $(\boldsymbol{\square})$ acetic acid; (A) ethanol; ( ) propan-2-ol; and the different sample introduction systems tested: (A) MWDS2, 290 W; (B) MWDS; (C) CS. Sample uptake rate: $100 \mu \mathrm{L} \mathrm{min}^{-1}$.

parameter is almost constant irrespective of $Q_{1}$ and the matrix tested. Nonetheless, an important effect of the sample introduction system has been observed. Thus, $\mathrm{Mg} \mathrm{II} / \mathrm{Mg}$ I lines ratio values are, on average, 4.5, 6.5 and 8.0 for MWDS2, MWDS and CS, respectively. The same relative behaviour has been observed for the $\mathrm{Cr} \mathrm{II} / \mathrm{Cr} \mathrm{I}_{\text {ratio }}{ }^{43}$ and $\mathrm{Ar}$ emission signal $^{44}$ measurements. Therefore it can be concluded that using the microwave-based systems, mainly the MWDS2, a higher amount of solvent is delivered to the plasma. Hence, a detrimental effect on the plasma excitation characteristics is observed. The higher heating efficiency of the MWDS2, together with the low efficiency of the condensation step used to remove the solvent vapour, are the responsible factors in these behaviours. In these conditions, it is easy to justify the lack of correspondence between emission signals and $W_{\text {tot }}$ values.

Influence of the line energy. Fig. 5 shows the effect of the line energy $\left(E_{\text {sum }}\right)$ on the emission intensity obtained with a given matrix relative to that obtained with water $\left(I_{\text {rel }}\right)$ for all the sample introduction systems operating at $100 \mu \mathrm{L} \min ^{-1}$ : MWDS2 (Fig. 5A), MWDS (Fig. 5B) and CS (Fig. 5C). From data in Fig. 4, it can be stated that, in general terms, there is no noticeable effect of $E_{\text {sum }}$ on $I_{\text {rel }}$ for all the matrices and sample introduction systems tested. Moreover, Fig. 5 also shows that the matrix effects due to the presence of organic solvent solutions are mitigated when operating with the microwavebased systems, mainly the MWDS2. Thus, when using the MWDS2 (Fig. 5A) there is little effect of the matrix nature on $I_{\text {rel }}$, these values being close to 1.0 in most cases. In fact, the average of the $I_{\text {rel }}$ values obtained for all lines and a complete set of solutions is $1.2 \pm 0.2$. When using the CS (Fig. 5C) the effect of the matrix nature is more pronounced, as was observed for Mn (Fig. 3C). The $I_{\text {rel }}$ values lie in the 1.3-3.1 range depending on the line considered, the average value being $2.0 \pm 0.5$. Once again, the behaviour of the MWDS (Fig. $5 \mathrm{~B})$ is intermediate between MWDS2 and CS ( $I_{\text {rel }}$ average value of $1.6 \pm 0.2$ ). Similar results have been obtained operating at $400 \mu \mathrm{L} \mathrm{min} \min ^{-1}$.

The results in Fig. 5 indicate that the use of the MWDS2 makes it possible to analyze samples of different organic matrices, at least in concentrations up to $10 \% \mathrm{w} / \mathrm{w}$, using a unique set of standards. It suggests that this system could be useful for "universal calibration". ${ }^{45-47}$ This is of a noticeable importance for the analysis of samples of unknown organic matrices or those showing a temporal variability in its solvent composition.

Precision. Table 6 gathers the relative standard deviation values (RSD) of the emission intensity obtained for all the sample introduction systems and matrices studied. These values are the minimum and maximum obtained for the emission signal of all the lines measured (Table 2). As can be seen in Table 6 , the RSD of the emission signal obtained with the MWDS2 is about $1-5 \%$ irrespective of the sample uptake rate and matrix considered. The CS provides similar values. When using the MWDS the precision of the emission signal depends on the solution employed, being higher (RSD up to $10 \%$ ) for ethanol and propan-2-ol. With this system, the sudden evaporation of the droplets impacting against the walls of the spray chamber deteriorates the stability of the system. ${ }^{37}$ On comparing both microwave systems, it can be concluded that the better control of the aerosol heating process afforded by the MWDS2 is responsible for the better signal precision values.

Limits of detection. The LOD obtained with all the matrices are of the same order of magnitude as those obtained with 
Table 6 Relative standard deviations of the emission signals obtained for all the sample introduction systems and matrices studied at different sample uptake rate

\begin{tabular}{|c|c|c|c|c|c|c|}
\hline \multirow[b]{3}{*}{ Solvent } & \multicolumn{6}{|c|}{ RSD $(\%)$} \\
\hline & \multicolumn{2}{|c|}{ SDMW2 } & \multicolumn{2}{|l|}{$\underline{\text { SDMW }}$} & \multicolumn{2}{|l|}{ CS } \\
\hline & $\begin{array}{l}100 \mu \mathrm{L} \\
\min ^{-1}\end{array}$ & $\begin{array}{l}400 \mu \mathrm{L} \\
\min ^{-1}\end{array}$ & $\begin{array}{l}100 \mu \mathrm{L} \\
\min ^{-1}\end{array}$ & $\begin{array}{l}400 \mu \mathrm{L} \\
\min ^{-1}\end{array}$ & $\begin{array}{l}100 \mu \mathrm{L} \\
\min ^{-1}\end{array}$ & $\begin{array}{l}400 \mu \mathrm{I} \\
\min ^{-1}\end{array}$ \\
\hline Water & $2-5$ & $3-5$ & $1-4$ & $2-5$ & $1-3$ & $1-3$ \\
\hline Formic acid & $1-5$ & $2-4$ & $2-5$ & $2-5$ & $2-5$ & $2-5$ \\
\hline Acetic acid & $1-5$ & $1-5$ & $2-5$ & $2-5$ & $1-5$ & $1-5$ \\
\hline Ethanol & $2-4$ & $2-4$ & $3-6$ & $4-10$ & $1-5$ & $2-5$ \\
\hline Propan-2-ol & $1-5$ & $2-5$ & $2-6$ & $4-10$ & $1-5$ & $1-5$ \\
\hline
\end{tabular}

water, irrespective of the sample introduction system used. The behaviour of the microwave-based systems is that expected from the emission signals shown in Fig. 5. Operating with the CS, the higher emission signals registered when using organic solvent solutions are counterbalanced by the higher instability of the blank and the higher background equivalent concentration (BEC). Thus, working at $400 \mu \mathrm{L} \mathrm{min}{ }^{-1}$, this parameter is 1.3 times higher (on average) for the organic matrices than for plain water solution. Similar results have been obtained operating at $100 \mu \mathrm{L} \mathrm{min}{ }^{-1}$.

Transient matrix effects. Fig. 6 registers the variation of the relative emission signal of Mn II obtained with the MWDS2 when the matrix is changed from water to $10 \%$ ethanol and vice versa. As can be observed, a signal transient effect occurs when changing the solution matrix. In both cases, a drift time of about $6 \mathrm{~min}$ is needed to reach the steady state signal value. This time is by far higher than the rinse out time observed for the MWDS2 operating with organic matrices (about 75 s). Fig. 6 also reveals that when switched from water to ethanol solution the signal increases up to $30 \%$ and then decreases until reaching the steady state. Conversely, when switching from ethanol to water, the signal decreases up to $20 \%$ and then increases until reaching the steady state. This behaviour has been similarly observed with other matrix combinations. When operating with the CS similar transient effects have been observed. Nonetheless, the stabilization time and signal varia-

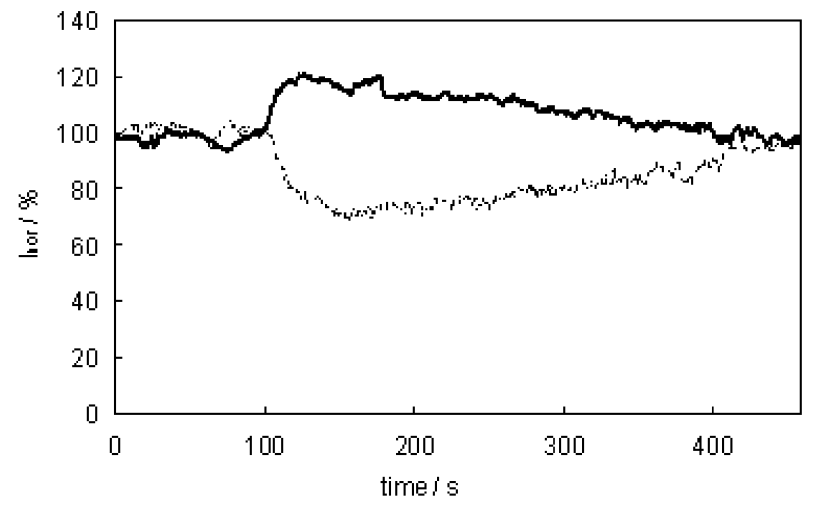

Fig. 6 Normalized ICP-AES response of Mn $257.610 \mathrm{~nm}$ on changing from water to $10 \%$ ethanol solution (continuous line) and from $10 \%$ ethanol to plain water solution (dotted line). MWDS2, MW incident power: $290 \mathrm{~W}$. Sample uptake rate: $400 \mu \mathrm{L} \mathrm{min}{ }^{-1}$. tions are lower than those observed with the MWDS2. Thus, the time needed by the CS to reach the steady state signal is just $80 \mathrm{~s}$ (4.5 times lower than that with the MWDS2), meanwhile the signal variations are of about $10 \%$ of the steady state value (about the half of those observed with the MWDS2). These findings are consistent with those previously reported by Olesik et al. $^{48}$ operating with acid solutions and using a double-pass spray chamber. These authors concluded that transient effects originate from changes to the extent of aerosol evaporation inside the sample introduction system due to changes in the aerosol volatility. From the above explanation it can be concluded that the use of a heated spray chamber should eliminate the transient effect. This prediction is in disagreement with the results shown by the MWDS2. This apparent contradiction can be justified taking into account that with the MWDS2 the aerosol heating extent depends on the matrix dissipation factor. Ethanol solution shows a higher $\operatorname{tg} \delta$ than water (Table 4) and, therefore, its aerosols are heated and evaporated more efficiently.

\section{Conclusions}

The results of the present study demonstrate that the MWDS2 can be successfully used as a sample introduction system for organic solvent solutions with a concentration up to $10 \% \mathrm{w} / \mathrm{w}$.

The use of a $\mathrm{TM}_{010}$ microwave cavity shows noticeable benefits for the introduction of organic solvent solutions in ICP-AES due to the possibility of controlling the aerosol heating process. Operating at the highest incident microwave power allowed, it is possible to operate up to $400 \mu \mathrm{L} \mathrm{min} \operatorname{mos}^{-1}$ without a signal drop. In these optimum conditions, the MWDS2 affords: (i) better analytical response than the MWDS and the CS for all matrices studied, due to the highest solution transport rates afforded by the MWDS2; and (ii) a noticeable reduction in the matrix effects due to the use of organic solvents in ICP-AES. Operating with the MWDS2, differences in the matrix properties become less of a determinant, thus giving rise to lower matrix effects than the MWDS and CS. For all the analytical lines and organic matrices tested, the MWDS2 gives rise to signal values closer to those obtained with plain water solutions than the MWDS and CS. This indicates that the MWDS2 would make it possible to use aqueous standards for the analysis of organic matrix samples (up to $10 \% \mathrm{w} / \mathrm{w}$ ). Experiments to demonstrate this approach are currently being carried out in our laboratories. As a negative aspect derived from the use of the MWDS2, it must be pointed out that transient matrix effects provided by this device are more pronounced than those observed when using a CS.

\section{Acknowledgements}

G. Grindlay thanks the University of Alicante for the fellowship.

\section{References}

1 R. I. Botto, J. Anal. At. Spectrom., 1993, 8, 51.

2 I. B. Brenner and E. Dorfman, Microchem. J., 1995, 52, 81. 
3 M. Montes-Bayón, K. Denicola and J. A. Caruso, J. Chromatogr. A, 2003, 1000, 457.

4 P. Giusti, D. Schaumlöffel, J. Ruiz Encinar and J. Spuznar, J. Anal. At. Spectrom., 2005, 10, 1101.

5 D. G. Weir and M. W. Blades, J. Anal. At. Spectrom., 1994, 9, 1311.

6 D. G. Weir and M. W. Blades, J. Anal. At. Spectrom., 1994, 9, 1323.

7 D. G. Weir and M. W. Blades, J. Anal. At. Spectrom., 1996, 11, 43.

8 D. G. Weir and M. W. Blades, J. Anal. At. Spectrom., 1996, 11, 1011.

9 A. W. Boorn and R. F. Browner, Anal. Chem., 1982, 54, 1402.

10 P. W. J. M. Boumans, Line coincidence tables for inductively coupled plasma emission spectrometry, Pergamon, Oxford, 1981.

11 B. L. Sharp, J. Anal. At. Spectrom., 1988, 3, 613.

12 J. Mora, V. Hernandis and A. Canals, J. Anal. At. Spectrom., 1991, 6, 573.

13 J. Mora, J. L. Todolí, A. Canals and V. Hernandis, J. Anal. At. Spectrom., 1997, 12, 445.

14 G. Kreuning and F. J. M. J. Maessen, Spectrochim. Acta, Part B, 1989, 44, 367

15 C. Pan, G. Zhu and R. F. Browner, J. Anal. At. Spectrom., 1990, 5, 537.

16 C. Pan, G. Zhu and R. F. Browner, J. Anal. At. Spectrom., 1992, 7, 1231.

17 P. Barrett and E. Pruszkowska, Anal. Chem., 1984, 56, 1927.

18 K. Kahen, A. Strubinger, J. Chirinos and A. Montaser, Spectrochim. Acta, Part B, 2003, 58, 397.

19 S. A. O'Brien, J. R. Chirinos, K. Jorabchi, K. Kahen, M. E. Cree and A. Montaser, J. Anal. At. Spectrom., 2003, 18, 910.

20 T. Maeda and K. Wagatsuma, Spectrochim. Acta, Part B, 2005, 60, 81.

21 J. L. Todolí and J. M. Mermet, J. Anal. At. Spectrom., 2002, 17, 211.

22 J. L. Todolí and J. M. Mermet, J. Anal. At. Spectrom., 2001, 16, 514.

23 M. Wind, A. Eisenmenger and W. Lehmann, J. Anal. At. Spectrom., 2002, 17, 21

24 H. P. Longerich and W. Diegor, J. Anal. At. Spectrom., 2001, 16, 1196.
25 A. Makarov and J. Szpunar, J. Anal. At. Spectrom., 1999, 14, 1323.

26 D. R. Wiederin, R. S. Houk, R. K. Winge and A. P. D'Silva, Anal. Chem., 1990, 62, 1155.

27 I. B. Brenner, A. Zander, M. Plantz and J. Zhu, J. Anal. At. Spectrom., 1997, 12, 273.

28 J. Mora, J. L. Todolí, I. Rico and A. Canals, Analyst, 1998, 123, 1229.

29 L. Gras, J. Mora, J. L. Todolí, V. Hernandis and A. Canals, Spectrochim. Acta, Part B, 1997, 52, 1201.

30 L. Gras, J. Mora, J. L. Todolí, A. Canals and V. Hernandis, Spectrochim. Acta, Part B, 1999, 54, 469.

31 J. Mora, A. Canals, V. Hernandis, E. H. van Veen and M. T. C. de Loos-Vollebregt, J. Anal. At. Spectrom., 1998, 13, 175.

32 J. Mora, L. Gras, E. H. van Veen and M. T. C. de Loos-Vollebregt, Spectrochim. Acta, Part B, 1999, 54, 959.

33 G. Grindlay, S. Maestre, J. Mora, V. Hernandis and L. Gras, J. Anal. At. Spectrom., 2005, 20, 455.

34 D. D. Smith and R. F. Browner, Anal. Chem., 1982, 54, 533.

35 L. Gras, J. Mora, J. L. Todolí, A. Canals and V. Hernandis, Spectrochim. Acta, Part B, 1999, 54, 1321.

$36 \mathrm{H}$. Contreras, PhD Thesis, University of Alicante, Spain, 2001.

37 M. A. Tarr, G. Zhu and R. F. Browner, J. Anal. At. Spectrom., 1992, 7, 813.

38 P. W. J. M. Boumans, Spectrochim. Acta, Part B, 1991, 46, 431.

39 P. W. J. M. Boumans, Spectrochim. Acta, Part B, 1991, 46, 917.

40 K. O. Douglass, N. Fitzgerald, B. J. Ingebrethsen and J. F. Tyson, Spectrochim. Acta, Part B, 2004, 59, 261.

41 A. Canals, L. Gras, J. Mora, V. Hernandis, J. Margineda, M. Rojo and J. Muñoz, Spectrochim. Acta, Part B, 1999, 54, 333.

42 A. C. Metaxas, Foundations of Electroheat, Wiley, New York, 1996.

43 E. H. van Veen and M. T. C. de Loos-Vollebregt, J. Anal. At. Spectrom., 1999, 14, 831.

44 I. Novotny, J. C. Farinas, J.-L. Wan, E. Poussel and J. M. Mermet, Spectrochim. Acta, Part B, 1996, 51, 1517.

45 A. A. Al-Ammar, R. K. Gupta and R. Barnes, J. Anal. At. Spectrom., 1999, 14, 801.

46 R. I. Botto and J. Zhu, J. Anal. At. Spectrom., 1994, 9, 905.

47 R. I. Botto and J. Zhu, J. Anal. At. Spectrom., 1996, 11, 675.

48 I. I. Stewart and J. W. Olesik, J. Anal. At. Spectrom., 1998, 13, 843. 